\title{
Antibacterial and protein-repellent dental composite for prevention of secondary caries
}

\author{
Ning Zhang* \\ Department of Orthodontics, School of Stomatology, Capital Medical University, Beijing, 100050, China
}

Biofilm acids lead to secondary caries, which is a main reason for dental restoration failures. Incorporation both protein-repellent and antibacterial agents into dental composite resulted in a much greater inhibition in biofilm activity. This new class of bioactive dental composite with antibacterial and protein-repellent properties is promising to prevent tooth decays and inhibit recurrent caries.

Dental caries is still prevalent, health and financial burden around the world. Resin composites, because of their esthetics and directfilling ability, are increasingly popular in tooth cavity restorations. However, previous studies have indicated that resin composites tend to accumulate more biofilm (plaque) than other restoratives [1]. Biofilms with acid production lead to secondary caries, which is a main reason for restoration failures [2]. Hence, it is beneficial to synthesize a new kind of anti-biofilm resin composites that can inhibit biofilm formation, thus preventing secondary caries. Several effective approaches are being investigated to develop a new generation of bioactive resin composites with anti-biofilm properties.

An important approach develops antibacterial resin composites by incorporating quaternary ammonium monomers (QAMs) in resins, to inhibit biofilm activity and lactic acid production. For example, 12-methacryloyloxydodecylpyridinium bromide (MDPB) [3] and methacryloxylethylcetyl dimethyl ammonium chloride (DMAE-CB) [4] could copolymerize in resins to impart an antibacterial function. Recently, a quaternary ammonium dimethacrylate (QADM) was added into resin composite, which exhibited great anti-biofilm properties $[5,6]$. The anti-biofilm mechanism of QAMs was reported to be that quaternary ammonium can lead to bacteria lysis by binding to cell membrane to cause cytoplasmic leakage [7]. When the bacterial cell contacts the QAM resin, the electric balance of cell membrane could be affected, leading to cell death [8]. Previous studies shown that the antibiofilm property of QAMs increased when the alkyl chain length (CL) was increased from 5 to 16 , and then decreased when CL was further increased to 18 [9,10]. A new dimethylaminohexadecyl methacrylate (DMAHDM) with CL of 16 was recently shown to have the strongest antibacterial activity among the QAMs tested [10].

A second method imparts a protein-repellent activity to resins, to repel proteins to the surface thus making it more difficult for bacteria to adhere to the surface. After the composite is exposed in the oral cavity, proteins are adsorbed onto its surface, which serve as a prerequisite for bacteria attachment $[11,12]$. The adsorption of oral bacteria to the resin composite is mediated by the adsorbed proteins $[11,12]$. Biofilm is the source of infection with organic acids leading to caries. Accordingly, it is desirable for the composite to be able to inhibit proteins and repel bacteria attachment, thereby reducing biofilm formation and caries. It was shown that most proteins were found to adsorb to hydrophobic surfaces [13]. In contrast, highly hydrophilic surface coatings using 2-methacryloyloxyethyl phosphorylcholine (MPC) are used to inhibit protein adsorption and bacterial attachment [14]. MPC is one of the most common hydrophilic bioactive polymers, which is a methacrylate with a phospholipid polar group in the side chain $[15,16]$. Various medical devices using MPC polymer have been synthesized and used clinically [14]. Regarding the mechanism of protein-repellency, it was reported that MPC is hydrophilic [15] and there is lots of free water but no bound water in the hydrated MPC polymer [16]. The bound water would lead to protein attachment $[16,17]$. In contrast, the free water around the phosphorylcholine group could repel proteins effectively, thereby inhibiting proteins [16,17]. Recently, MPC was added into dental resins and bonding agents, achieving a great protein-repellent property $[18,19]$.

A third approach combines multiple bioactive agents for synergistic effects. For example, MPC was combined with DMAHDM to synthesize a resin composite with a combination of antibacterial and protein-repellent abilities [20]. The novel MPC-DMAHDM containing composite greatly inhibited protein adsorption and bacterial viability without compromising the mechanical properties [20]. Combination of MPC and DMAHDM achieved biofilm reduction efficacy that was much stronger than that using MPC or DMAHDM alone [20]. The reason for the synergistic effect of using MPC and DMAHDM together is likely that the salivary protein coating on resin surfaces in vivo could decrease the contact-inhibition efficacy of DMAHDM [21,22]. Hence, because of the protein-repellent ability of MPC, the resin surface had much less proteins and was more exposed with direct contact against bacteria and biofilms, thereby increasing the contact-inhibition efficacy of DMAHDM. Therefore, using dual agents of MPC and DMAHDM synergistically may have wide applicability to other dental materials.

\section{References}

1. Beyth N, BahirR, Matalon S, Domb AJ, Weiss EI (2008) Streptococcus mutans biofilm changes surface-topography of resin composites. Dent Mater 24: 732-736.[Crossref]

2. Sakaguchi RL (2005) Review of the current status and challenges for dental posterior restorative composites: clinical, chemistry, and physical behavior considerations. Dent Mater 21: 3-6.[Crossref]

3. Imazato S (2009) Bio-active restorative materials with antibacterial effects: new dimension of innovation in restorative dentistry. Dent Mater J 28: 11-19.[Crossref]

Correspondence to: Ning Zhang, Department of Orthodontics, School of Stomatology, Capital Medical University, Beijing, 100050, China, E-mail: dentistzhang112@163.com

Received: January 03, 2017; Accepted: January 11, 2017; Published: January 14, 2017 
4. Li F, Chen J, Chai Z, Zhang L, Xiao Y, et al. (2009) Effects of a dental adhesive incorporating antibacterial monomer on the growth, adherence and membrane integrity of streptococcus mutans. J Dent 37: 289-296.[Crossref]

5. Cheng L, Weir MD, Zhang K, Xu SM, Chen Q, et al. (2012) Antibacterial nanocomposite with calcium phosphate and quaternary ammonium. J Dent Res 91: 460-466.[Crossref]

6. Zhou C, Weir MD, Zhang K, Deng D, Cheng L, et al. (2013) Synthesis of new antibacterial quaternary ammonium monomer for incorporation into CaPnanocomposite. Dent Mater29: 859-870.[Crossref]

7. Beyth N, Yudovin-Farber I, Bahir R, Domb AJ, Weiss EI (2006) Antibacterial activity of dental composites containing quaternary ammonium polyethylenimine nanoparticles against Streptococcus mutans. Biomaterials 27: 3995-4002.[Crossref]

8. Namba N, Yoshida Y, Nagaoka N, Takashima S, Matsuura-Yoshimoto K, et al. (2009) Antibacterial effect of bactericide immobilized in resin matrix. Dent Mater 25: 424 430. [Crossref]

9. He J, Soderling E, Osterblad M, Vallittu PK, Lassila LVJ (2011) Synthesis of methacrylate monomers with antibacterial effects against S. mutans. Molecules 16: 9755-9763.[Crossref]

10. Zhou H, Li F, Weir MD, Xu HH (2013) Dental plaque microcosm response to bonding agents containing quaternary ammonium methacrylates with different chain lengths and charge densities. J Dent 41: 1122-1131. [Crossref]

11. Busscher HJ, Rinastiti M, Siswomihardjo W, van der Mei HC (2010) Biofilm formation on dental restorative and implant materials. J Dent Res89: 657-665.[Crossref]

12. Reich M, Kümmerer K, Al-Ahmad A, Hannig C (2013) Fatty acid profile of the initial oral biofilm (pellicle): an in-situ study. Lipids 48: 929-937.[Crossref]

13. Katsikogianni M, Missirlis YF (2004)Concise review of mechanisms of bacteria adhesion to biomaterials and of techniques used in estimating bacteria material interactions. Eur Cells Mater 8: 37-57.[Crossref]

14. Lewis AL, Tolhurst LA, Stratford PW (2002) Analysis of a phosphorylcholine-based polymer coating on a coronary stent pre-and post-implantation. Biomaterials 23: 16971706.[Crossref]

15. Ishihara K, Ueda T, Nakabayashi N (1990) Preparation of phospholipid polymers and their properties as polymer hydrogel membranes. Polymer $J$ 22: 355-360.

16. Ishihara K, Nomura H, Mihara T, Kurita K, Iwasaki Y, et al. (1998) Why do phospholipid polymers reduce protein adsorption? J Biomed Mater Res 39: 323-330.[Crossref]

17. Yamasaki A, Imamura Y, Kurita K, Iwasaki Y, Nakabayashi N, et al. (2003) Surface mobility of polymers having phosphorylcholine groups connected with various bridging units and their protein adsorption-resistance properties. Colloid Surface B28: 53-62.

18. Zhang N, Melo MA, Bai Y, Xu HH (2014) Novel protein-repellent dental adhesive containing 2-methacryloyloxyethyl phosphorylcholine. J Dent 42: 1284-1291. [Crossref]

19. Zhang N, Chen C, Melo MA, Bai Y, Cheng L, et al. (2015) A novel protein-repellent dental composite containing 2-methacryloyloxyethyl phosphorylcholine. Int J Oral Sci 7: 103-109.[Crossref]

20. Zhang N, Ma J, Melo MA, Weir MD, Bai Y, et al. (2015) Protein-repellent and antibacterial dental composite to inhibit biofilms and caries. $J$ Dent 43: 225-234. [Crossref]

21. Müller R, Eidt A, Hiller KA, Katzur V, Subat M, et al. (2009) Influences of protein films on antibacterial or bacteria-repellent surface coatings in a model system using silicon wafers. Biomaterials 30: 4921-4929.[Crossref]

22. Li F, Weir MD, Fouad AF, Xu HH (2014) Effect of salivary pellicle on antibacterial activity of novel antibacterial dental adhesives using a dental plaque microcosm biofilm model. Dent Mater 30: 182-191.[Crossref]

Copyright: (C2016 Zhang N. This is an open-access article distributed under the terms of the Creative Commons Attribution License, which permits unrestricted use, distribution, and reproduction in any medium, provided the original author and source are credited. 